\title{
Synthesis of Tetrachloro, Tetraiodo, and Tetraazido Double-Decker Siloxanes
}

Yujia Liu, ${ }^{a, b}$ Mana Kigure, ${ }^{b}$ Kyoka Koizumi, ${ }^{b}$ Nobuhiro Takeda, ${ }^{b}$ Masafumi Unno ${ }^{* a, b}$ and Armelle Ouali ${ }^{* a, c}$

${ }^{a}$ Gunma University Initiative for Advanced Research (GIAR)-International Open Laboratory with Institute Charles Gerhardt Montpellier (UMR5253 CNRS-UM-ENSCM), France. Gunma University, Kiryu 376-8515, Japan

${ }^{\mathrm{b}}$ Department of Chemistry and Chemical Biology, Graduate School of Science and Technology. Gunma University, Kiryu 376-8515, Japan

${ }^{c}$ Institut Charles Gerhardt Montpellier, UMR 5253 CNRS-UM-ENSCM. ENSCM, 8 rue de l'Ecole Normale, 34296 Montpellier Cedex 05, France

\begin{abstract}
A convenient and scalable (gram-scale) route to unprecedented $\mathrm{T}_{8} \mathrm{D}_{2}$-DDSQs bearing four chloro- (3b) or four azido (5b) groups is reported. Both compounds were characterized and proved to undergo successfully nucleophilic substitution for $\mathbf{3 b}$ (with iodide or azide) and coppercatalyzed azide-alkyne [3+2] cycloaddition for $\mathbf{5 b}$. All these transformations occurred under mild conditions and the corresponding DDSQs were prepared in very high yields. Beyond the enhanced multivalency as compared to the previously described di-substituted $\mathrm{D}_{2} \mathrm{~T}_{8}$ structures, the reported tetra-functional DDSQs are formed as a single isomer and readily isolated in very high yields. Moreover, the tetra-azido DDSQ $\mathbf{5 b}$ constitutes a multipurpose nano-building block for the further preparation of new inorganic-organic hybrid materials where the covalent incorporation of a DDSQ moiety brings valuable properties.
\end{abstract}




\section{Introduction}

Polyhedral oligomeric silsesquioxanes (POSSs), compounds with a rigid inorganic core composed of Si-O-Si bonds framework surrounded by organic groups, find increasing applications in various fields including polymers, ${ }^{1}$ sensors,${ }^{2}$ catalysis,${ }^{3}$ host-guest complexes, ${ }^{4}$ organic light-emitting $\operatorname{diodes}^{5}$ or porous materials ${ }^{6} \cdot{ }^{7}$ While a wide array of mono- or octafunctional derivatives of $\mathrm{T}_{8}$ silsesquioxanes have been described, ${ }^{8}$ the double-decker siloxanes (DDSQs) bearing reactive substituents have been less studied (Scheme 1). Both open $\mathbf{M}_{4} \mathbf{T}_{\mathbf{8}}$ (DDSQ-4OSi, Scheme 1a) and closed $\mathbf{D}_{\mathbf{2}} \mathbf{T}_{\mathbf{8}}$ (DDSQ-2OSi, Scheme 1b) frameworks are yet applied in various areas of chemistry such as coordination chemistry, ${ }^{9}$ optics ${ }^{10}$ or hybrid polymer nanocomposites ${ }^{11} .{ }^{12}$ To include DDSQ architectures in more complex systems (for example coordination complexes, electronic or optic devices, hybrid polymers, and so on), the pre-requisite consists in decorating the $\mathbf{M}_{4} \mathbf{T}_{8}$ and $\mathbf{D}_{2} \mathbf{T}_{8}$ DDSQ architectures with reactive groups (Scheme $1 \mathrm{a}$ and $1 \mathrm{~b}$ respectively). Therefore functionalizable versions were reported with $\mathbf{M}_{\mathbf{4}} \mathbf{T}_{\mathbf{8}}$ structures bearing for example four hydrogen, alkenyl or silylalkynyl groups, prone to undergo hydrosilylation or silylative couplings respectively (Scheme 1a). ${ }^{12,13}$ In the same way, related $\mathbf{D}_{\mathbf{2}} \mathbf{T}_{\mathbf{8}}$ involving two reactive groups (one on each external D-type silicon atom) such as hydrogen, ${ }^{14}$ alkenyl, ${ }^{15}$ amino, ${ }^{16}$ chloro $^{17}$ or azido ${ }^{18}$ were described as well (Scheme 1b).

(a) $M_{4} T_{8}$

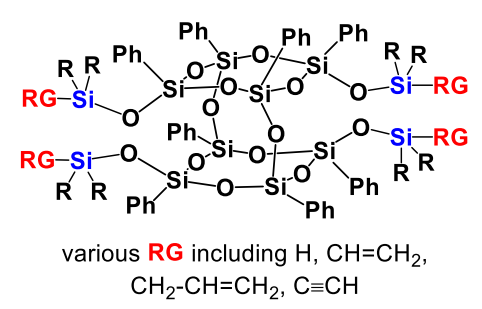

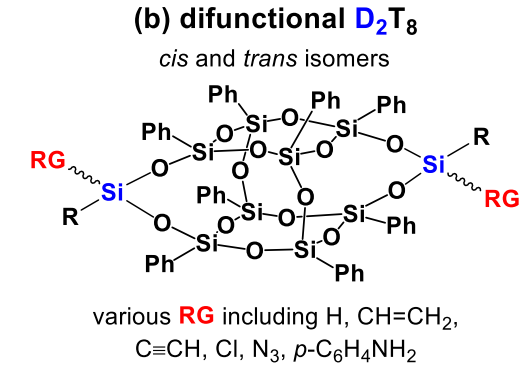

$R G=$ reactive group $R=$ alkyl, aryl (c) tetrafunctional $D_{2} T_{8}$

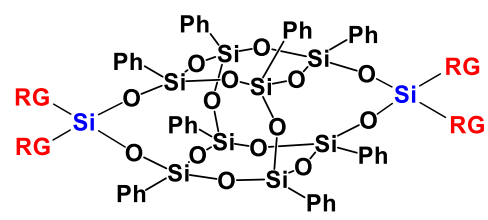

previous work $\mathrm{RG}=\mathrm{CH}=\mathrm{CH}_{2}, \mathrm{CH}_{2}-\mathrm{CH}=\mathrm{CH}_{2}$ this work: $R G=-\left(\mathrm{CH}_{2}\right)_{3}-\mathrm{SiCH}_{2} \mathrm{X}, \mathrm{X}=\mathrm{Cl}, \mathrm{I}, \mathrm{N}_{3}$

Scheme 1. General structures of double-decker siloxanes (DDSQs) and reactive groups (RG) reported 
It is worthy to note that the number of reactive groups grafted on the inorganic core appears as decisive to define the further properties of the $\operatorname{POSSs}^{13 a}$ as illustrated by the strongly different behaviours of mono- or polysubstituted POSS in a given application. For example, $\mathrm{T}_{8}$ bearing one boron-dipyrromethene fluorophore displayed significantly better lasing efficiency and photostability than their octafunctionalized counterparts while multivalency is a strong asset for catalytic or biological applications. ${ }^{8}$ The fine tuning of external functional groups on the POSS thus constitutes a strategic challenge. Along these lines, we recently described the first tetrafunctional $\mathrm{D}_{2} \mathrm{~T}_{8}$ DDSQs decorated with four vinyl- and allyl moieties (Scheme 1c). ${ }^{19}$ To open the way to new applications, the discovery of tetrafunctional DDSQs bearing key reactive groups such as azides is of great importance. Indeed the copper-catalyzed Huisgen [3+2] cycloaddition (CuAAC) involving an azide and an alkyne is highly attractive in terms of atom-economy, high yield and also for the robustness of the triazole ring it generates. ${ }^{20}$ This ligation method is widely exploited to functionalize molecules or nano-objects for preparing functional materials. Therefore, azido-containing POSSs with several inorganic frameworks have been reported. Most examples involve $\mathrm{T}_{8}$ bearing one ${ }^{21,22}$ or eight ${ }^{23,24}$ azido terminal functions connected to the inorganic core through aliphatic or benzylic spacers. These cubic silsesquioxanes were functionalized via the CuAAC strategy to access to hybrid polymeric materials, ${ }^{21,23}$ bio-active compounds, ${ }^{24}$ or recyclable catalysts. ${ }^{22} \mathrm{~T}_{10}$-POSSs and $\mathrm{D}_{2} \mathrm{~T}_{8}$ DDSQs respectively decorated by ten or two azido substituents were significantly less explored although the preliminary reports demonstrate that they constitute interesting building blocks to design hybrid polymers ${ }^{18 b, 25}$ or recyclable catalysts. ${ }^{22 \mathrm{c}}$ In this work, a synthetic route to an unprecedented tetraazido $\mathrm{D}_{2} \mathrm{~T}_{8}$ DDSQ is described. Moreover, the proof of concept of its successful functionalization through CuAAC is provided to reach nitrogen-rich compounds prone to be of interest in several application fields. In addition, the 
described and characterized intermediate tetrachloro- and tetraiodo- DDSQs constitute appealing functionalizable building blocks for the preparation of organic-inorganic hybrid materials as well.

\section{RESULTS AND DISCUSSION}

Previously described tetravinyl 1a and tetraallyl DDSQ 1b were allowed to react with (chloromethyl)dimethylsilane ${ }^{26} \mathbf{2}$ in the presence of Karstedt's catalyst ( $~ 0.02 \mathrm{~mol} \%$ Pt per olefin group) and in both cases, the disappearance of the signals corresponding to olefinic signals was observed (Scheme 2). In the case of 1a, the quantitative functionalization of vinyl groups required a temperature of $40{ }^{\circ} \mathrm{C}$ while the hydrosilylation of $\mathbf{1 b}$ occurred selectively at $25{ }^{\circ} \mathrm{C}$. The corresponding tetrachloro-DDSQ 3a was obtained in $81 \%$ yield after recrystallization and the pure compound $\mathbf{3 b}$ could be isolated in quantitative yield after a straightforward filtration through a silica and celite plug.

As expected, both ${ }^{29} \mathrm{Si}$ spectra of $\mathbf{3 a}$ and $\mathbf{3 b}$ clearly displayed two singlets for the non-equivalent T-unit silicon atoms of the core (Figure 1a and 1b), the resonances at -79.60 and $-79.10 \mathrm{ppm}$ (respectively for 3a and $\mathbf{3 b}$ ) being assigned to the internal T-group silicon atoms ( $\mathrm{Si}$ in green) and those at -78.52 and -78.27 being assigned to the T-group silicon atoms (red color) nearest to the D-group silicon atoms (blue color). The latter gave rise to a singlet at around -19.4 ppm for both compounds and lastly, the ${ }^{29} \mathrm{Si}$ resonances at 5.36 and $3.39 \mathrm{ppm}$ have been assigned to the silicon atoms of the carbosilane pattern (pink color) of $\mathbf{3 a}$ and $\mathbf{3 b}$ respectively. Moreover, the data obtained from ${ }^{1} \mathrm{H}$ and ${ }^{13} \mathrm{C}$ NMR were in accordance with the molecular structures (see supporting information). Then single crystals were grown and the structures of $\mathbf{3 a}$ and $\mathbf{3 b}$ could be determined by X-ray crystallography (Figures 2 and 3, respectively). Both structures have similar framework, with Si-O-Si bond lengths in the ranges of 1.599(6)-1.639(6) $\AA$ (average 1.617(6) $\AA$ ) for 3a and $1.598(0)-1.632(0) \AA$ (average 1.615(0) $\AA$ ) for $3 \mathbf{b}$ which are in accordance with previously reported 
related DDSQs derived from the $\mathbf{1 a}$ and $\mathbf{1 b} .{ }^{19} \mathrm{Si}-\mathrm{C}$ lengths, in the ranges of $1.828-1.894 \AA$ (average $1.858 \AA$ ) for $\mathbf{3 a}$ and of $1.760-1.980 \AA$ (average $1.860 \AA$ ) for $\mathbf{3 b}$ were also consistent with those found for related compounds obtained after hydrosilylation with dimethylphenylsilane of 1a (in the ranges of $1.843-1.889 \AA$ (average $1.858 \AA$ )) or $\mathbf{1 b}\left(1.844-1.885 \AA\right.$ (average $1.861 \AA$ )). ${ }^{19}$ Besides, in $\mathbf{3 a}$, the $\mathrm{Si}-\mathrm{O}-\mathrm{Si}$ bond angles vary from 138.9 to $174.6^{\circ}$ and in $\mathbf{3 b}$, the $\mathrm{Si}-\mathrm{O}-\mathrm{Si}$ bond angles are in the range of $143.3-177.5^{\circ}$. The large deviation of the bond angles indicates the flexible structure of the frameworks. ${ }^{8 b}$

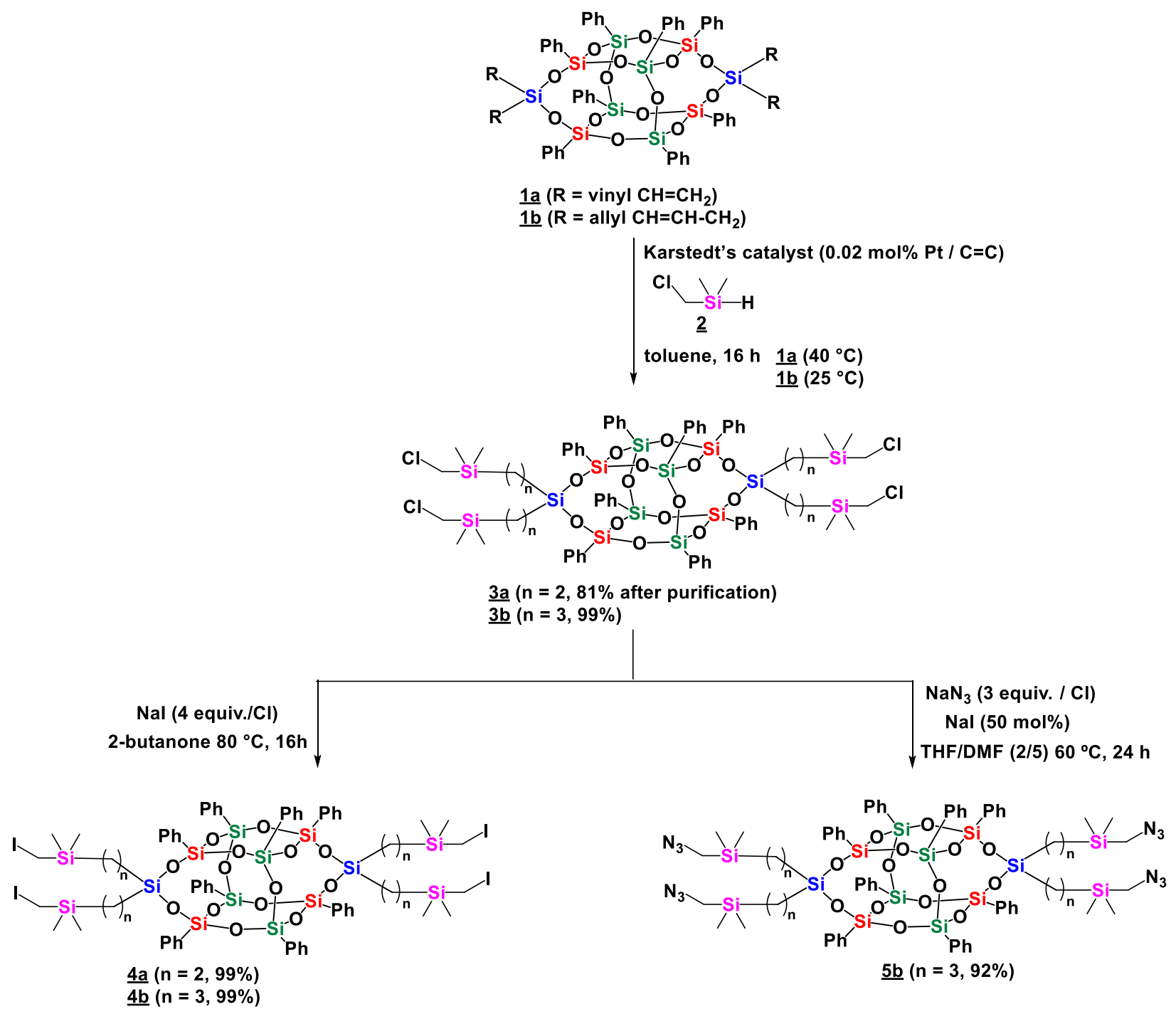

Scheme 2. Synthetic routes to tetrachloro, tetraiodo and tetraazido-DDSQs. 


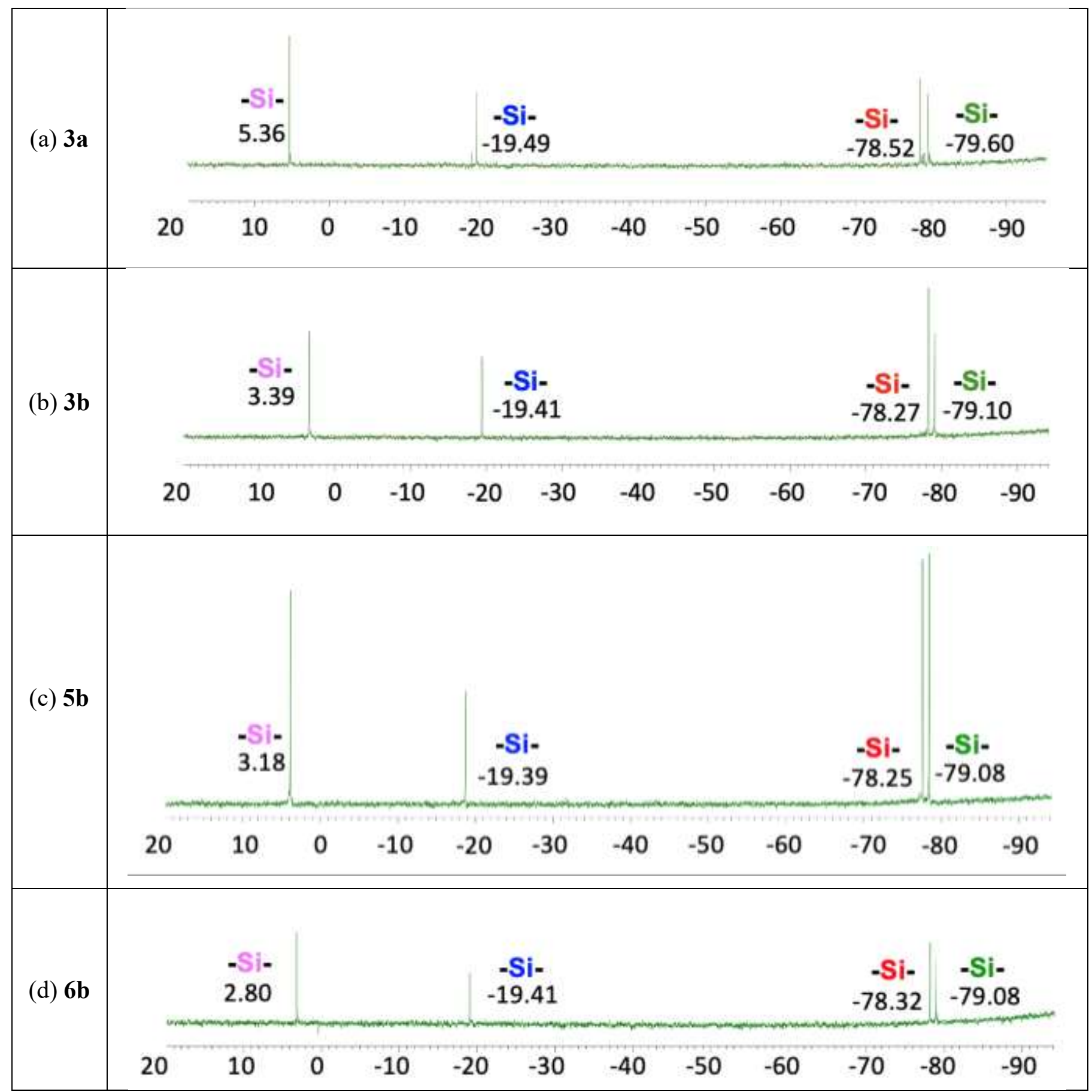

Figure 1. ${ }^{29} \mathrm{Si} \mathrm{NMR} \mathrm{spectra} \mathrm{(in} \mathrm{CDCl}_{3}$ ) for the DDSQs $\mathbf{3 a}, \mathbf{3 b}, \mathbf{5 b}$, and $\mathbf{6} \mathbf{b}$. Chemical shifts are in ppm unit. 


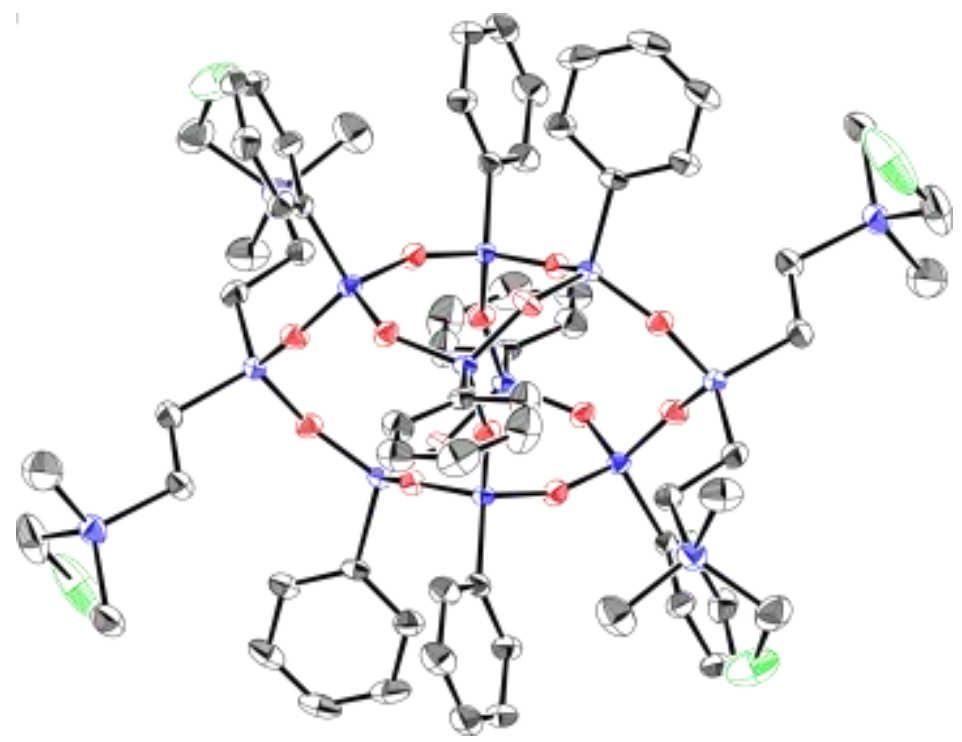

Figure 2. Crystal structure of one fragment of two nonidentical molecules 3a. Black: carbon; blue: silicon; red: oxygen; green: chlorine. Thermal ellipsoids are shown at the $50 \%$ probability level. All hydrogen atoms are omitted for clarity.

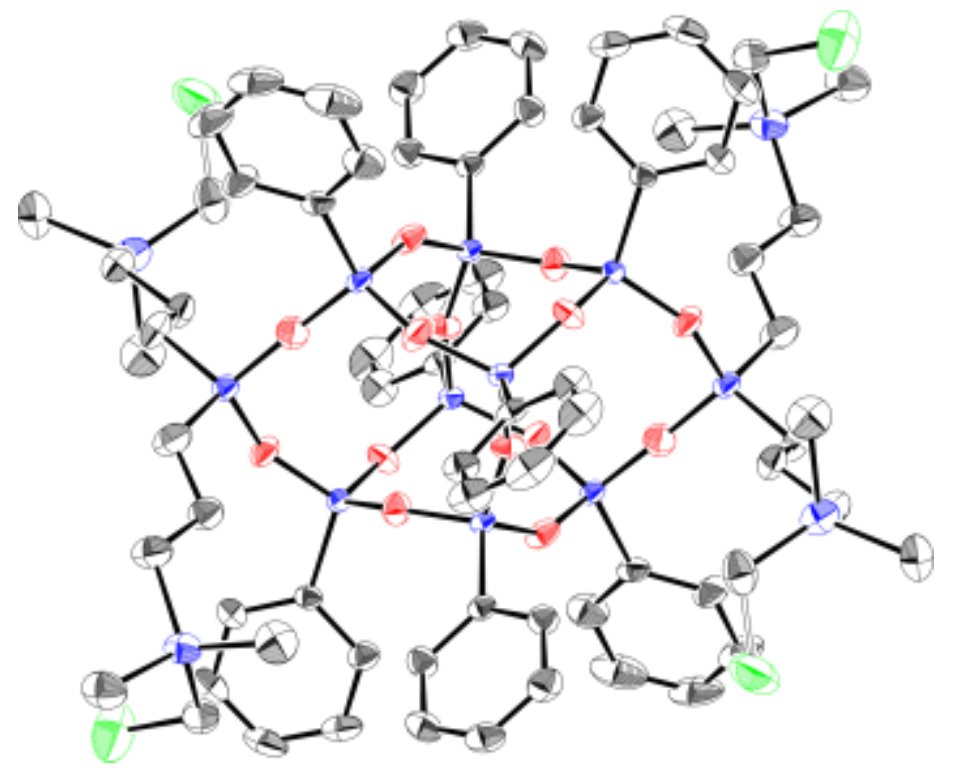

Figure 3. Crystal structure of 3b. Black: carbon; blue: silicon; red: oxygen; green: chlorine. Thermal ellipsoids are shown at the 50\% probability level. All hydrogen atoms and minor parts of the disordered $\mathrm{CH}_{2} \mathrm{Cl}$ and $\mathrm{CH}_{3}$ groups are omitted for clarity. 
The chloro substituents of $\mathbf{3 a}$ and $\mathbf{3 b}$ could be quantitatively replaced by iodides through halide exchange in the presence of sodium iodide (Scheme 2). Resulting DDSQs $\mathbf{4 a}$ and $\mathbf{4 b}$ could be isolated in quantitative yields and fully characterized (multinuclear NMRs and mass spectroscopy, X-ray structures for $\mathbf{4 a}$, see SI). These compounds represent useful building blocks for further functionalizations, iodides being easier to substitute as compared to parent chlorides.

It is worthy to note that when scaling up to the gram scale, the preparation of 3a through hydrosilylation of $\mathbf{1 a}$ with $\mathbf{2}$ occurred not selectively and the purification revealed difficult. Despite several attempts of purifications including column chromatography, gel permeation chromatography, washings and crystallization, $\mathbf{3 a}$ could not be obtained from minor impurities likely due to the partial polymerization of the $\mathrm{C}=\mathrm{C}$ bonds. Therefore the following functionalizations were performed with the tetrachloro-DDSQ $\mathbf{3 b}$, readily prepared in gram scale.

Next the chloro-decorated double-decker siloxane $\mathbf{3 b}$ was allowed to react with sodium azide in a THF/DMF mixture. The use of sub-stoichiometric amounts of sodium iodide greatly accelerated the nucleophilic substitution that proceeded more rapidly and selectively. Compound $\mathbf{3 b}$ yielded quantitatively and selectively to $\mathbf{5 b}$, the first double-decker structure bearing four azido groups. The ${ }^{29} \mathrm{Si}$ spectrum of $\mathbf{5 b}$ displayed the four expected singlets, analogous to those described in the cases of $\mathbf{3 a}$ and $\mathbf{3 b}(-79.08$ and $-78.25 \mathrm{ppm}$ for the $\mathrm{T}$ silicon atoms of the core in green and red, respectively, $-19.39 \mathrm{ppm}$ for the $\mathrm{D}$ silicon atoms in blue and $3.18 \mathrm{ppm}$ for the carbosilane in pink, Figure 1c). By ${ }^{1} \mathrm{H}$ NMR, the singlet assigned to the methylene group in the alpha position of the carbosilane (pink Si) next to the chloro-substituent in $\mathbf{3 b}$ was found to be affected to a very small extent by the substitution with the azido group ( $2.55 \mathrm{ppm}$ in $\mathbf{3 b}$ to $2.50 \mathrm{ppm}$ in $\mathbf{5 b}$, see $\mathrm{SI})$. However, by ${ }^{13} \mathrm{C}$ NMR, the signal of the same methylene group significantly shifted from 30.42 ppm in $\mathbf{3 b}$ to $40.95 \mathrm{ppm}$ in $\mathbf{5 b}$ thus confirming the successful and quantitative substitution. These 
chemical shifts in ${ }^{1} \mathrm{H}$ and ${ }^{13} \mathrm{C}$ NMR are in accordance with those reported for related compounds bearing the Si- $\mathrm{CH}_{2}-\mathrm{X}$ moiety $\left(\mathrm{X}=\mathrm{Cl}\right.$ or $\left.\mathrm{N}_{3}\right) .{ }^{27}$ The structure of $\mathbf{5 b}$ could be confirmed by ${ }^{1} \mathrm{H}$ and ${ }^{13} \mathrm{C}$ NMR as well. Moreover, the infra-red spectrum highlighted the characteristic band corresponding to the azido group at $2090 \mathrm{~cm}^{-1}$. Lastly, crystals were grown and the structure of $\mathbf{5 b}$ could be determined by X-ray crystallography (Figure 4 and SI). Si-O bond lengths (in the ranges of 1.578-1.638 $\AA$; average $1.610 \AA$ ) and $\mathrm{Si}-\mathrm{O}-\mathrm{Si}$ bond angles (from 145.4 to 177.5 ) were found to be similar to those of $\mathbf{3 b}$.

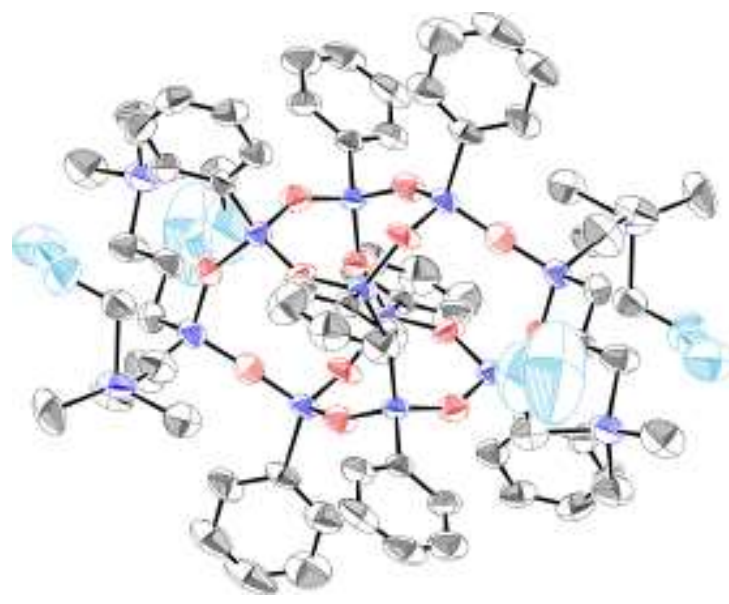

Figure 4. Crystal structure of one fragment of two nonidentical molecules 5b. Black: carbon; blue: silicon; sky blue: nitrogen; red: oxygen. Thermal ellipsoids are shown at the $50 \%$ probability level. All hydrogen atoms and minor parts of the disordered $\left(\mathrm{CH}_{2}\right)_{3} \mathrm{Si}\left(\mathrm{CH}_{3}\right)_{2} \mathrm{CH}_{2} \mathrm{~N}_{3}$ groups are omitted for clarity.

As expected, the results of thermogravimetric analysis (TGA) under $\mathrm{N}_{2}$ showed a lower $\mathrm{Td}_{5}(167$ ${ }^{\circ} \mathrm{C}$, see SI Table S2) for azido DDSQ $\mathbf{5 b}$ as compared to those of tetra-chloro-DDSQs $\mathbf{3 a}$ and $\mathbf{3 b}$ (371 and $359^{\circ} \mathrm{C}$ respectively) displaying a very high thermal stability. 

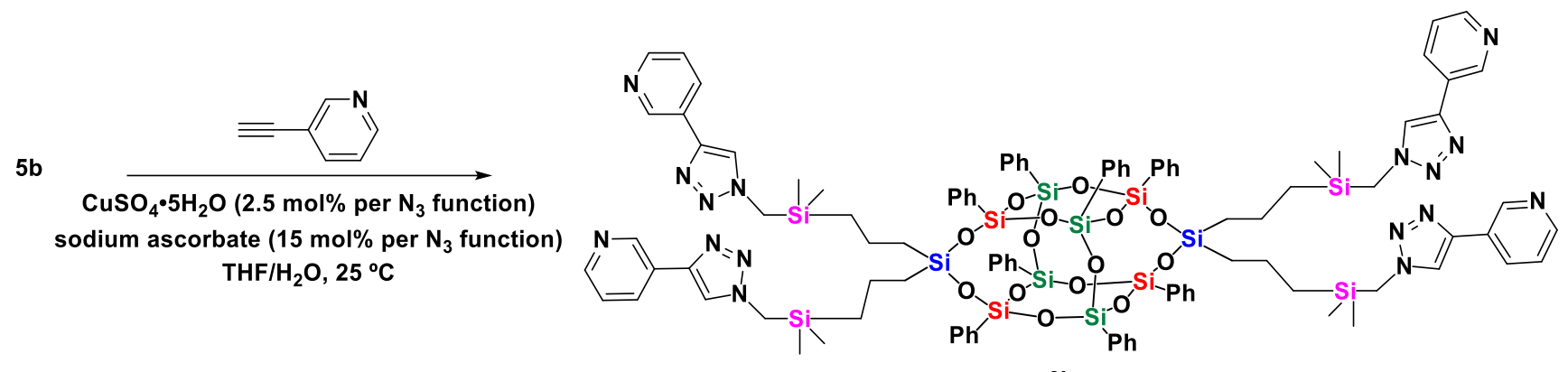

$6 b$

Scheme 3. Functionalization of the four azido groups via copper-catalyzed [3+2] cycloaddition

The reactivity of the external azido substituents was next evaluated. For a representative example, $\mathbf{5 b}$ was allowed to react through copper-catalyzed Huisgen [3+2] cycloaddition with 3ethynylpyridine, a challenging substrate often requiring harsh reaction conditions (Scheme 3 ). ${ }^{28}$ The reaction was proceeded selectively under mild conditions at room temperature and the corresponding DDSQ $\mathbf{6 b}$ bearing four peripheric pyridines was isolated in $84 \%$ yield after washing with $5 \% \mathrm{NH}_{4} \mathrm{OH}$ aqueous solution. The structure of this compound was confirmed by multinuclear NMRs and mass spectroscopies. The ${ }^{29} \mathrm{Si} \mathrm{NMR}$ is given as a representative characterization and the four expected singlets (Figure 1d) could be assigned to the silicon atoms from the core (Si in red and green, -79.08 and $-78.32 \mathrm{ppm}$ ), to the internal D-group silicon atoms (Si in blue, -19.41 $\mathrm{ppm}$ ) and to the carbosilane-type silicon atoms ( $\mathrm{Si}$ in pink, $2.80 \mathrm{ppm}$ ). Besides, the presence of a singlet at $7.34 \mathrm{ppm}\left({ }^{1} \mathrm{H} \mathrm{NMR}\right)$ and of a signal at $123.9 \mathrm{ppm}\left({ }^{13} \mathrm{C} \mathrm{NMR}\right)$ were consistent with the successful formation of the triazole ring. ${ }^{28}$ Mass spectroscopy also confirmed the structure. It is worthy to note that the triazole-3-ethynyl moiety possesses interesting properties as ligand for transition metals (Pt, Re for e. g.) and the resulting complexes were shown to present appealing properties in the field of medicine. ${ }^{29}$ For example, Pt complexes displayed very high cytotoxicity activity on malignant cells, even higher than cisplatin. Grafting such complexes onto reported 
DDSQs may lead to nanosized drugs possibly interesting in terms of controlled delivery. Besides, the multivalency, well-known key parameter for biological applications, ${ }^{24}$ will be enabled by the DDSQ architecture described in this paper which opens new prospects in this field. More generally, the cycloaddition with other alkynes will offer new opportunities to reach unprecedented multivalent structures having different and new properties as compared to the corresponding monomer, $\mathrm{T}_{8}, \mathrm{~T}_{10}$ or di-substituted $\mathrm{D}_{2} \mathrm{~T}_{8}$-analogs.

\section{Conclusion}

In summary, a convenient and scalable (gram-scale) route to unprecedented $\mathrm{T}_{8} \mathrm{D}_{2}$-DDSQs bearing four chloro- (3b) or four azido (5b) groups was proposed. Both compounds were characterized and proved to undergo successfully nucleophilic substitution for the former (with iodide or azide) and copper-catalyzed azide-alkyne [3+2] cycloaddition for the latter. It is noteworthy that the tetraiodo DDSQ (4b), more reactive than its chloro counterpart, will be of significant interest in the case of poorly reactive nucleophiles. All the transformations occurred under mild conditions and the DDSQs were prepared in very high yields. Beyond the enhanced multivalency as compared to the previously reported di-substituted $\mathrm{D}_{2} \mathrm{~T}_{8}$ structures, the reported tetra-functional DDSQs are formed as a single isomer and readily isolated in very high yields. Moreover, the tetra-azido DDSQ 5b constitutes a multipurpose nano-building block for the further preparation of new inorganicorganic hybrid materials where the covalent incorporation of a DDSQ moiety brings valuable properties. As mentioned above, the concerned application fields are numerous. To name only a few, the further functionalization of $\mathbf{5 b}$ with chromophores, ${ }^{10}$ sugars $^{24}$ or metal complexes ${ }^{22}$ will surely contribute to design new photonic materials for optoelectronic devices, new multivalent bioconjugates for in vivo applications or recyclable catalysts for developing greener processes 
respectively. Along these lines, studies centered on applications of reported DDSQs are currently underway in our laboratories.

EXPERIMENTAL SECTION. All reactions were performed under argon atmosphere using standard Schlenk technique. THF and DMF were dried using mBRAUN purification system. Toluene was distilled from calcium hydride, stored on $4 \AA$ activated molecular sieves under an argon atmosphere. 2-Butanone was distilled from sodium sulfate, stored on $4 \AA$ activated molecular sieves under an argon atmosphere. (Chloromethyl)dimethylsilane and Karstedt's catalyst (in xylene, $2 \% \mathrm{Pt}$ ) were purchased from Sigma-Aldrich, sodium azide, sodium ascorbate and 3-ethynylpyridine were purchased from TCI, copper (II) sulfate pentahydrate and sodium iodide were purchased from FUJIFILM Wako Pure Chemical Co. Chemical Reagents and all these reagents were used as received, without further purification. The Fourier transformation nuclear magnetic resonance (NMR) spectra were obtained using a JEOL JNM-ECA $600\left({ }^{1} \mathrm{H}\right.$ at 600.17 $\mathrm{MHz},{ }^{13} \mathrm{C}$ at $150.91 \mathrm{MHz},{ }^{29} \mathrm{Si}$ at $119.24 \mathrm{MHz}$ ) NMR instrument. For ${ }^{1} \mathrm{H} \mathrm{NMR}$, chemical shifts are reported as $\delta$ units (ppm) relative to $\mathrm{SiMe}_{4}$ (TMS) and the residual solvents peaks were used as standards. For ${ }^{13} \mathrm{C}$ NMR and ${ }^{29} \mathrm{Si} \mathrm{NMR}$, chemical shifts are reported as $\delta$ units (ppm) relative to $\mathrm{SiMe}_{4}$ (TMS), the residual solvents peaks were used as standards and spectra were obtained with complete proton decoupling. MALDI-TOF mass analysis were carried out with a Shimadzu AXIMA Performance instrument using 2,5-dihydroxybenzoic acid (dithranol) as the matrix. All reagents used were of analytical grade. Elemental analyses were performed by the Center for Material Research by Instrumental Analysis (CIA), Gunma University, Japan. IR spectra were measured with a Shimadzu FTIR-8400S. TGA was carried out under a nitrogen flow $\left(250 \mathrm{~mL} \mathrm{~min}^{-}\right.$ ${ }^{1}$ ) with a heating rate $10{ }^{\circ} \mathrm{C} \mathrm{min}^{-1}$. All samples were measured with temperatures ranging from 50 to $1000{ }^{\circ} \mathrm{C}$, where they remained for $5 \mathrm{~min}$. The weight loss and heating rate were continuously recorded along the experiment.

Synthesis of 3a. After standard cycles of evacuation and backfilling with dry and pure argon, an oven-dried Schlenk flask equipped with a magnetic stirring bar was charged with 1a (123 mg, 0.1 mmol), distilled toluene $(0.6 \mathrm{~mL})$ and (chloromethyl)dimethylsilane $2(72 \mu \mathrm{L}, 0.6 \mathrm{mmol})$. And then Karstedt's catalyst $\left[9.8 \times 10^{-5} \mathrm{mmol}[\mathrm{Pt}], 112 \mu \mathrm{L}\right.$ of a pre-prepared [Pt] solution (diluted 100 times from a commercial bottle ( $2 \%$ platinum in xylene) in distilled toluene)] was added at room temperature under argon. After the addition, the reaction mixture was allowed to heat to $40{ }^{\circ} \mathrm{C}$ and 
to stir for $16 \mathrm{~h}$ at $40{ }^{\circ} \mathrm{C}$. The reaction mixture was cooled down to room temperature and then passed through a silica and celite plug which was washed twice with toluene and twice with dichloromethane. The gathered filtrate was evaporated to afford a crude product, which was further purified by recrystallization from chloroform and 2-propanol to give 3a (134 $\mathrm{mg}, 81 \%)$ as a colorless crystal. Analysis data for 3a. MALDI-TOF MS (m/z): $1687.75\left([\mathrm{M}+\mathrm{Na}]^{+}\right.$, calcd 1687.42). Elemental analysis: Calcd for $\mathrm{C}_{68} \mathrm{H}_{88} \mathrm{Cl}_{4} \mathrm{O}_{14} \mathrm{Si}_{14} \cdot 2 \mathrm{H}_{2} \mathrm{O}$ : $\mathrm{C}, 49.07 ; \mathrm{H}, 5.33$. Found: $\mathrm{C}$, 48.03; H, 5.45. ${ }^{1} \mathrm{H}$ NMR (600.17 MHz, $\left.\mathrm{CDCl}_{3}\right): \delta=-0.04(\mathrm{~s}, 24 \mathrm{H}), 0.61-0.70(\mathrm{~m}, 16 \mathrm{H}), 2.62(\mathrm{~s}$, 8H), 7.21-7.29 (m, 16H), 7.37-7.45 (m, 16H), 7.55-7.56 (m, 8H). ${ }^{13} \mathrm{C}\left\{{ }^{1} \mathrm{H}\right\}$ NMR (150.91 MHz, $\left.\mathrm{CDCl}_{3}\right): \delta=-5.15,4.71,6.93,29.91,127.89,128.01,130.61,130.64,131.11,132.13,134.10$, 134.18 ppm. ${ }^{29} \mathrm{Si}\left\{{ }^{1} \mathrm{H}\right\}$ NMR $\left(119.24 \mathrm{MHz}, \mathrm{CDCl}_{3}\right): \delta=5.36,-19.49,-78.52,-79.60 \mathrm{ppm}$.

Synthesis of 3b. After standard cycles of evacuation and backfilling with dry and pure argon, an oven-dried Schlenk flask equipped with a magnetic stirring bar was charged with $\mathbf{1 b}$ (643 $\mathbf{m g}, 0.5$ $\mathrm{mmol})$, distilled toluene $(3.0 \mathrm{~mL})$ and (chloromethyl)dimethylsilane (365 $\mu \mathrm{L}, 3.0 \mathrm{mmol})$. And then Karstedt's catalyst [4.9 x $10^{-4} \mathrm{mmol}[\mathrm{Pt}], 280 \mu \mathrm{L}$ of a pre-prepared [Pt] solution (diluted 50 times from a commercial bottle ( $2 \%$ platinum in xylene) in distilled toluene)] was added at room temperature under argon. After the addition, the reaction mixture was allowed to stir for $16 \mathrm{~h}$ at room temperature $\left(25^{\circ} \mathrm{C}\right)$. The reaction mixture was passed through a silica and celite plug which was washed twice with toluene and twice with dichloromethane. The gathered filtrate was evaporated to give $\mathbf{3 b}$ ( $860 \mathrm{mg}$, 99\%) as a slightly yellowish solid, without any further purification. Analysis data for 3b. MALDI-TOF MS (m/z): $1744.03\left([\mathrm{M}+\mathrm{Na}]^{+}\right.$, calcd 1743.53). Elemental analysis: Calcd for $\mathrm{C}_{72} \mathrm{H}_{96} \mathrm{Cl}_{4} \mathrm{O}_{14} \mathrm{Si}_{14} \cdot \mathrm{H}_{2} \mathrm{O}: \mathrm{C}, 49.74 ; \mathrm{H}, 5.68$. Found: $\mathrm{C}, 49.39 ; \mathrm{H}, 5.60 .{ }^{1} \mathrm{H}$ NMR $\left(600.17 \mathrm{MHz}, \mathrm{CDCl}_{3}\right): \delta=-0.10(\mathrm{~s}, 24 \mathrm{H}), 0.61-0.64(\mathrm{~m}, 8 \mathrm{H}), 0.82-0.84(\mathrm{~m}, 8 \mathrm{H}), 1.44-1.47(\mathrm{~m}$, $8 \mathrm{H}), 2.55(\mathrm{~s}, 8 \mathrm{H}), 7.22-7.28(\mathrm{~m}, 16 \mathrm{H}), 7.37-7.45(\mathrm{~m}, 16 \mathrm{H}), 7.53-7.55(\mathrm{~m}, 8 \mathrm{H}) .{ }^{13} \mathrm{C}\left\{{ }^{1} \mathrm{H}\right\} \mathrm{NMR}$ $\left(150.91 \mathrm{MHz}, \mathrm{CDCl}_{3}\right): \delta=-4.66,17.26,17.97,20.22,30.42,127.90,128.00,130.57,130.61$, $131.15,132.19,134.07,134.21 \mathrm{ppm} .{ }^{29} \mathrm{Si}\left\{{ }^{1} \mathrm{H}\right\}$ NMR (119.24 MHz, $\left.\mathrm{CDCl}_{3}\right): \delta=3.39,-19.41,-$ 78.27, -79.10 ppm.

Note: Hydrosilylation of $\mathbf{1 a}$ and $\mathbf{1 b}$ exclusively gave rise to the formation of the terminal regioisomer, 3a and $\mathbf{3 b}$, respectively (internally silylated products not observed).

Synthesis of 4a. After standard cycles of evacuation and backfilling with dry and pure argon, an oven-dried Schlenk flask equipped with a magnetic stirring bar was charged with 3a (167 mg, 0.1 
$\mathrm{mmol})$ and distilled 2-butanone $(1.3 \mathrm{~mL})$. Sodium iodide $(240 \mathrm{mg}, 1.6 \mathrm{mmol})$ was then added into the mixture at room temperature under argon. The reaction mixture was allowed to heat to reflux $\left(80{ }^{\circ} \mathrm{C}\right.$ ) and to stir for $16 \mathrm{~h}$ at $80{ }^{\circ} \mathrm{C}$. The reaction mixture was cooled down to room temperature and then filtered. The filtrate was evaporated under reduced pressure and then dissolved in chloroform. The solution was washed twice with water and the aqueous layers were extracted twice with chloroform. The organic layers were gathered, dried over anhydrous sodium sulfate and concentrated under reduced pressure to afford the desired product $4 \mathbf{a}(201 \mathrm{mg}, 99 \%)$ as a yellowish solid, without any further purification. Analysis data for 4a. MALDI-TOF MS (m/z): 2053.33 $\left([\mathrm{M}+\mathrm{Na}]^{+}\right.$, calcd 2053.24). ${ }^{1} \mathrm{H}$ NMR $\left(600.17 \mathrm{MHz}, \mathrm{CDCl}_{3}\right): \delta=-0.031(\mathrm{~s}, 24 \mathrm{H}), 0.58-0.60(\mathrm{~m}$, $8 \mathrm{H}), 0.67-0.70(\mathrm{~m}, 8 \mathrm{H}), 1.81(\mathrm{~s}, 8 \mathrm{H}), 7.20-7.22(\mathrm{~m}, 8 \mathrm{H}), 7.25-7.28(\mathrm{~m}, 8 \mathrm{H}), 7.36-7.44(\mathrm{~m}, 16 \mathrm{H})$, 7.54-7.56 (m, 8H). ${ }^{13} \mathrm{C}\left\{{ }^{1} \mathrm{H}\right\}$ NMR $\left(150.91 \mathrm{MHz}, \mathrm{CDCl}_{3}\right): \delta=-13.81,-3.69,5.90,7.05,127.93$, 128.02, 130.60, 130.68, 131.13, 132.15, 134.14, 134.24 ppm. ${ }^{29} \mathrm{Si}\left\{{ }^{1} \mathrm{H}\right\}$ NMR $(119.24 \mathrm{MHz}$, $\left.\mathrm{CDCl}_{3}\right): \delta=6.98,-19.04,-78.11,-79.19 \mathrm{ppm}$.

Synthesis of $4 \mathbf{b}$. After standard cycles of evacuation and backfilling with dry and pure argon, an oven-dried Schlenk flask equipped with a magnetic stirring bar was charged with $\mathbf{3 b}$ (172 $\mathrm{mg}, 0.1$ $\mathrm{mmol}$ ) and distilled 2-butanone $(1.3 \mathrm{~mL})$. Sodium iodide $(240 \mathrm{mg}, 1.6 \mathrm{mmol})$ was then added into the mixture at room temperature under argon. The reaction mixture was allowed to heated to reflux $\left(80{ }^{\circ} \mathrm{C}\right.$ ) and to stir for $16 \mathrm{~h}$ at $80{ }^{\circ} \mathrm{C}$. The reaction mixture was cooled down to room temperature and then filtered. The filtrate was evaporated under reduced pressure and then dissolved in chloroform. The solution was washed twice with water and the aqueous layers were extracted twice with chloroform. The organic layers were gathered, dried over anhydrous sodium sulfate and concentrated under reduced pressure to afford the desired product $\mathbf{4 b}(207 \mathrm{mg}, 99 \%)$ as a slightly yellowish gel, without any further purification. Analysis data for $\mathbf{4 b}$. MALDI-TOF MS (m/z): $2109.40\left([\mathrm{M}+\mathrm{Na}]^{+}\right.$, calcd 2109.34). ${ }^{1} \mathrm{H}$ NMR $\left(600.17 \mathrm{MHz}, \mathrm{CDCl}_{3}\right): \delta=-0.089$ (s, 24H), 0.62$0.65(\mathrm{~m}, 8 \mathrm{H}), 0.80-0.83(\mathrm{~m}, 8 \mathrm{H}), 1.40-1.45(\mathrm{~m}, 8 \mathrm{H}), 1.74(\mathrm{~s}, 8 \mathrm{H}), 7.21-7.28(\mathrm{~m}, 16 \mathrm{H}), 7.36-7.44$ (m, 16H), 7.52-7.54 (m, 8H). ${ }^{13} \mathrm{C}\left\{{ }^{1} \mathrm{H}\right\} \operatorname{NMR}\left(150.91 \mathrm{MHz}, \mathrm{CDCl}_{3}\right): \delta=-12.99,-3.09,17.40,19.13$, $20.20,127.95,128.02,130.59,130.63,131.16,132.19,134.09,134.23$ ppm. ${ }^{29} \mathrm{Si}\left\{{ }^{1} \mathrm{H}\right\}$ NMR $\left(119.24 \mathrm{MHz}, \mathrm{CDCl}_{3}\right): \delta=4.49,-19.39,-78.32,-79.15 \mathrm{ppm}$.

Synthesis of 5b. After standard cycles of evacuation and backfilling with dry and pure argon, an oven-dried Schlenk flask equipped with a magnetic stirring bar was charged with $\mathbf{4 b}$ (860 mg, 0.5 $\mathrm{mmol}$ ), sodium iodide (38 mg, $0.25 \mathrm{mmol}$ ) and sodium azide (390 mg, $6.0 \mathrm{mmol})$. Dry THF (14.4 
$\mathrm{mL})$ and dry DMF (36 $\mathrm{mL})$ were then added into the mixture at room temperature under argon with vigorous stirring. The reaction mixture was allowed to heated to $60{ }^{\circ} \mathrm{C}$ and to stir for $24 \mathrm{~h}$ at $60{ }^{\circ} \mathrm{C}$. The reaction mixture was cooled down to room temperature, dichloromethane was slowly added and the mixture was stirred for about 10 minutes. And then ice was added into the mixture which was stirred for additional 30 minutes. The organic layer was then washed twice with brine, dried over anhydrous sodium sulfate and evaporated on the rotavapor (with dichloromethane several times to remove traces of DMF) to afford the desired product $\mathbf{5 b}(804 \mathrm{mg}, 92 \%)$ as a light yellowish solid, without any further purification. Analysis data for 5b. MALDI-TOF MS (m/z). $1959.82\left(\left[\mathrm{M}-4 \mathrm{~N}_{2}+\mathrm{Na}\right]^{+}\right.$, calcd 1959.75). ${ }^{1} \mathrm{H} \mathrm{NMR}\left(600.17 \mathrm{MHz}, \mathrm{CDCl}_{3}\right): \delta=-0.13(\mathrm{~s}, 24 \mathrm{H}), 0.57-$ $0.61(\mathrm{~m}, 8 \mathrm{H}), 0.82-0.84(\mathrm{~m}, 8 \mathrm{H}), 1.41-1.45$ (m, 8H), 2.50 (s, 8H), 7.23-7.29 (m, 16H), 7.39-7.46 $(\mathrm{m}, 16 \mathrm{H}), 7.52-7.54(\mathrm{~m}, 8 \mathrm{H}) .{ }^{13} \mathrm{C}\left\{{ }^{1} \mathrm{H}\right\} \mathrm{NMR}\left(150.91 \mathrm{MHz}, \mathrm{CDCl}_{3}\right): \delta=-4.30,17.24,18.30,20.19$, $40.95,127.91,128.03,130.64,130.68,131.14,132.14,134.07,134.21$ ppm. ${ }^{29} \mathrm{Si}\left\{{ }^{1} \mathrm{H}\right\} \mathrm{NMR}$ $\left(119.24 \mathrm{MHz}, \mathrm{CDCl}_{3}\right): \delta=3.18,-19.39,-78.25,-79.08 \mathrm{ppm}$.

Synthesis of 6b. After standard cycles of evacuation and backfilling with dry and pure argon, an oven-dried Schlenk flask equipped with a magnetic stirring bar was charged with $\mathbf{5 b}$ (87 $\mathbf{m g}, 0.05$ mmol), 3-ethynylpyridine $(27 \mathrm{mg}, 0.27 \mathrm{mmol})$ and dry THF $(1.6 \mathrm{~mL})$. To this solution mixture, $10 \mu \mathrm{L}$ of copper (II) sulfate pentahydrate degassed aqueous solution $(62 \mathrm{mg} / \mathrm{mL})$ and sodium ascorbate $(3 \mathrm{mg}, 0.015 \mathrm{mmol})$ were added under argon. The solution was allowed to stir at $25{ }^{\circ} \mathrm{C}$ for 3 days. Additional $10 \mu \mathrm{L}$ of copper sulfate pentahydrate degassed aqueous solution $(62 \mathrm{mg} / \mathrm{mL})$ and sodium ascorbate $(3 \mathrm{mg}, 0.015 \mathrm{mmol})$ were added under argon into the reaction mixture which was allowed to stir for additional 1 day at $25^{\circ} \mathrm{C}$. And then $5 \% \mathrm{NH}_{4} \mathrm{OH}$ aqueous solution was added into the reaction mixture which was extracted 3 times with dichloromethane. The collected organic layer was then washed twice with $5 \% \mathrm{NH}_{4} \mathrm{OH}$ aqueous solution and 3 times with water and dried over anhydrous sodium sulfate. The solvents were evaporated on the rotavapor to give a crude product which was further dried under vacuum at $100{ }^{\circ} \mathrm{C}$ for 2 hours (to remove the excess of 3ethynylpyridine) to afford the desired product $\mathbf{6 b}(90 \mathrm{mg}, 84 \%)$ as a slightly yellowish solid. Analysis data for 6b. ESI-HRMS: m/z found: 2159.5916 (calculated: 2159.5725). ${ }^{1} \mathrm{H}$ NMR $\left(600.17 \mathrm{MHz}, \mathrm{CDCl}_{3}\right): \delta=-0.12(\mathrm{~s}, 24 \mathrm{H}), 0.62-0.66(\mathrm{~m}, 8 \mathrm{H}), 0.77-0.81(\mathrm{~m}, 8 \mathrm{H}), 1.41-1.47(\mathrm{~m}$, $8 \mathrm{H}), 3.60(\mathrm{~s}, 8 \mathrm{H}), 7.14-7.17(\mathrm{~m}, 8 \mathrm{H}), 7.21-7.43(\mathrm{~m}, 32 \mathrm{H}), 7.48-7.51(\mathrm{~m}, 8 \mathrm{H}), 8.12(\mathrm{dt}, J=8.01$ $\mathrm{Hz}, 1.95 \mathrm{~Hz}, 4 \mathrm{H}), 8.54$ (d, J=3.21 Hz, 4H), 8.90 (sbr, 4H). ${ }^{13} \mathrm{C}\left\{{ }^{1} \mathrm{H}\right\} \mathrm{NMR}\left(150.91 \mathrm{MHz}, \mathrm{CDCl}_{3}\right)$ : $\delta=-4.15,17.13,18.15,20.02,40.91,120.72,123.92,127.14,127.98,128.10,130.76,130.81$, 
131.01, 131.89, 132.92, 133.96, 134.08, 144.27, 147.03, 149.13 ppm. ${ }^{29} \mathrm{Si}\left\{{ }^{1} \mathrm{H}\right\}$ NMR (119.24

$\left.\mathrm{MHz}, \mathrm{CDCl}_{3}\right): \delta=2.80,-19.41,-78.32,-79.08 \mathrm{ppm}$.

Crystallography. For crystal data, data collection, and refinement, see SI. CCDC-1971229 for 3a, CCDC-1971230 for 3b, CCDC-1971231 for 4a, CCDC-2021410 for $\mathbf{5 b}$ contain the supplementary crystallographic data for this paper.

\title{
ASSOCIATED CONTENT
}

Supporting Information: ${ }^{1} \mathrm{H},{ }^{13} \mathrm{C},{ }^{29} \mathrm{Si} N \mathrm{NM}$ spectra for compounds $\mathbf{3 a}, \mathbf{3 b}, \mathbf{4 a}, \mathbf{4 b}, \mathbf{5 b}$ and $\mathbf{6 b}$, IR spectra and thermal properties (TGA) for $\mathbf{3 a}, \mathbf{3 b}, \mathbf{5 b}$, crystallographic data for $\mathbf{3 a}, \mathbf{3 b}, \mathbf{4 a}$ and 5b. The Supporting Information is available free of charge on the ACS Publications website.

\section{AUTHOR INFORMATION}

\section{Corresponding Authors}

\begin{abstract}
Masafumi Unno. Department of Chemistry and Chemical Biology, Graduate School of Science and Technology, Gunma University, Kiryu 376-8515, Gunma, Japan; orcid.org/0000-0003-2158-1644; Email: unno@gunma-u.ac.jp Armelle Ouali. Institut Charles Gerhardt Montpellier ICGM, Univ. Montpellier, CNRS, ENSCM, Montpellier 34090, France; orcid.org/0000-0001-7436-776X. Email: armelle.ouali@enscm.fr.
\end{abstract}

\section{Authors}

Yujia Liu. Gunma University Initiative for Advanced Research (GIAR)-International Open Laboratory with Institute Charles Gerhardt Montpellier (UMR5253 CNRS-UM-ENSCM), France. Gunma University, Kiryu 376-8515, Japan. Department of Chemistry and Chemical Biology, Graduate School of Science and Technology. Gunma University, Kiryu 376-8515, Japan Institut Charles Gerhardt Montpellier ICGM, Univ. Montpellier, CNRS, ENSCM, Montpellier 34090, France.

Nobuhiro Takeda. Department of Chemistry and Chemical Biology, Graduate School of Science and Technology. Gunma University, Kiryu 376-8515, Japan

Mana Kigure. Department of Chemistry and Chemical Biology, Graduate School of Science and Technology. Gunma University, Kiryu 376-8515, Japan

Kyoka Koizumi. Department of Chemistry and Chemical Biology, Graduate School of Science and Technology. Gunma University, Kiryu 376-8515, Japan

\section{Notes}

The authors declare no competing financial interest.

\section{ACKNOWLEDGMENT}

The authors acknowledge the Gunma University Initiative for Advanced Research (GIAR) for funding the Open International Laboratory and the grant to Y. L, CNRS and New Energy and Industrial Technology Development Organization (NEDO) for funding, and JASSO for M. K. and K. K. travel grants to Montpellier.

\section{REFERENCES}

(1) (a) Li, J.; Dong, F.; Lu, L.; Li, H.; Xiong, Y.; Ha, C.-S. Raspberry-Like Polysilsesquioxane Particles with HollowSpheres-on-Sphere Structure: Rational Design, Controllable Synthesis, and Catalytic Application. Polymers 2019, 11, 1350; (b) Xu, S.; Zhao, B.; Wei, K.; Zheng, S. Organic-inorganic polyurethanes with double decker silsesquioxanes in the main chains: Morphologies, surface hydrophobicity, and shape memory properties. J. Polym. Sci. Pol. Phys. 2018, 56, 893-906.

(2) Kunthom, R.; Piyanuch. P.; Wanichacheva, N.; Ervithayasuporn, V. Cage-like silsesquioxanes bearing rhodamines as fluorescence $\mathrm{Hg}^{2+}$ sensors. J. Photochem. Photobiol. A 2018, 356, 248-255. 
(3) (a) Kunthom, R.; Jaroentomeechai, T.; Ervithayasuporn, V. Polyhedral oligomeric silsesquioxane (POSS) containing sulfonic acid groups as a metal-free catalyst to prepare polycaprolactone. Polymer 2017, 108, 173-178; (b) Mohapatra, S.; Chaiprasert, T.; Sodkhomkhum, R.; Kunthom, R.; Hanprasit, S.; Sangtrirutnugul, P.; Ervithayasuporn, V. Solid-state Synthesis of Polyhedral Oligomeric Silsesquioxane-Supported $N$-Heterocyclic Carbenes/Imidazolium salts on Palladium Nanoparticles: Highly Active and Recyclable Catalyst. ChemistrySelect 2016, $1,5353-5357$.

(4) (a) Chanmungkalakul, S.; Ervithayasuporn, V.; Boonkitti, P.; Phuekphong, A.; Prigyai, N.; Kladsomboon, S.; Kiatkamjornwong, S. Anion identification using silsesquioxane cages. Chem. Sci. 2018, 9, 7753-7765. (b) Aziz, E.Y.; Taylor, G.P.; Bassindale, R.A.; Coles, J.S.; Pitak, B.M. Synthesis and Structures of Novel Molecular Ionic Compounds Based on Encapsulation of Anions and Cations. Organometallics 2016, 35, 4004-4013.

(5) Walczak, M.; Januszewski, R.; Majchrzak, M.; Kubicki, M.; Dudziec, B.; Marciniec, B. Unusual cis and trans architecture of dihydrofunctional double-decker shaped silsesquioxane and synthesis of its ethyl bridged $\pi$ conjugated arene derivatives. New J. Chem. 2017, 41, 3290-3296.

(6) Liu, H.; Liu, H. Selective dye adsorption and metal ion detection using multifunctional silsesquioxane-based tetraphenylethene-linked nanoporous polymers. J. Mater. Chem. A 2017, 5, 9156-9162.

(7) Du, Y.; Liu, H. Cage-like Silsesquioxanes-based Hybrid Materials. Dalton Trans. 2020, 49, 5396-5405.

(8) (a) Laine, R. M.; Roll, M. F. Polyhedral Silsesquioxanes. Macromolecules 2011, 44, 1073-1109; (b) Cordes, D. B.; Lickiss, P. D.; Rataboul, F. Recent Developments in the Chemstry of Cubic Polyhedral Oligosilsesquioxanes. Chem. Rev. 2010, 110, 2081-2173; (c) Cordes, D. B.; Lickiss, P. D. in Applications of Polyhedral Oligomeric Silsesquioxanes, Advances in Silicon Science 3, ed. Hartmann-Thompson, C. Springer, 2011.

(9) (a) Espinas, J.; Pelletier; Abou-Hamad, E.; Emsley, L.; Basset, J.-M. A Silica-Supported Double-Decker Silsesquioxane Provides a Second Skin for the Selective Generation of Bipodal Surface Organometallic Complexes. Organometallics 2012, 31, 7610-7617; (b) Hay, M. T., Seurer, B.; Holmes, D.; Lee, A. A Novel Linear Titanium(IV)-POSS Coordination Polymer. Macromolecules 2010, 43, 2108-2110.

(10) (a) Pérez-Ojeda, M. E.; Trastoy, B.; Lopez-Arbeloa, I.; Banuelos, J.; Costela, A.; Garcia-Moreno, I.; Chiara, J. L. Click Assembly of Dye-Functionalized Octasilsesquioxanes for Highly Efficient and Photostable Photonic Systems. Chem. Eur. J. 2011, 17, 13258-13268; (b) Kohri, M.; Matsui, J.; Watanabe, A.; Miyashita, T. Synthesis and Optoelectronic Properties of Completely Carbazole-substituted Double-decker-shaped Silsesquioxane. Chem. Lett. 2010, 39, 1162-1163.

(11) (a) Kucuk, A. C., Matsui, J.; Miyashita, T. Effects of Subphase Composition on the Monolayer Behavior of "core-coronae" type Hybrid Amphiphiles. Thin Solid Films 2013, 534, 577-583; (b) Kucuk, A. C., Matsui, J.; Miyashita, T. Proton-Conducting Electrolyte Film of Double-Decker-Shaped Polyhedral Silsesquioxane Containing Covalently Bonded Phosphonic Acid Groups. J. Mater. Chem. 2012, 22, 3853-3858; (c) Kucuk, A. C., Matsui, J.; Miyashita, T. Effects of Hydrogen Bonding on the Monolayer Properties of Amphiphilic Double-Decker-Shaped Polyhedral Silsesquioxanes. Langmuir 2011, 27, 6381-6388. (d) Kucuk, A. C., Matsui, J.; Miyashita, T. LangmuirBlodgett Films Composed of Amphiphilic Double-Decker Shaped Polyhedral Oligomeric Silsesquioxanes. J. Colloid Interface Sci. 2011, 355, 106-114.

(12) Dudziec, B.; Marciniec, B. Double-Decker Silsesquioxanes: Current Chemistry and Applications. Current Org. Chem. 2017, 21, 2794-2813.

(13) (a) Rzonsowska, M.; Zmudzinska, K.; Duszczak, J.; Mituła, K.; Dudziec, B.; Żak, P. Synthesis of (Multi)Silylalkynyl-Substituted Silsesquioxanes Obtained via Silylative Coupling Reaction. Organometallics 2020, 39, 74-79; (b) Mituła, K. Duszczak, J.; Brząkalski, D.; Dudziec, B.; Kubicki, M.; Marciniec, B. Tetra-Functional Double-Decker Silsesquioxanes as Anchors for Reactive Functional Groups and Potential Synthons for Hybrid Materials. Chem. Commun. 2017, 53, 10370-10373; (c) Grzelak, M.; Frąckowiak, D.; Marciniec, B. VinylFunctionalized Silsesquioxanes and Germasilsesquioxanes. Eur. J. Inorg. Chem. 2017, 3337-3342.

(14) (a) Zhang, X.; Chi, H., Li, T.; Wang, F.; Chin, W-S, Xu, J. Energy Transfer Along a Sequence Controlled Hybrid Polymer. J. Polym. Sci. Part A: Polym. Chem. 2018, 56, 1225-1233; (b) Au-Yeung, H.-L.; Leung, S. Y.-L.; Yam, V. W.-W. Supramolecular assemblies of Dinuclear Alkynylplatinum(II)terpyridine Complexes with Double-Decker Silsesquioxane nano-cores: the Role of Isomerism in Constructing Nano-Structures. Chem. Commun. 2018, 54, 4128-4131; (c) Cao, J.; Fan, H.; Li, B.-G.; Zhu, S. Synthesis and Evaluation of Double-Decker Silsesquioxanes as Modifying Agent for Epoxy Resin. Polymer 2017, 124, 157-167; (d) Wei, Y.; Jiang, Q.; Hao, J.; Mu, J. Comparative Synthesis and Properties of POSS-based Fluorinated Poly(ether)sulfone Random Terpolymers. RSC Adv., 2017, 7 , 3914-3920; (e) Liu N.; Zheng, S. Organic-Inorganic Poly( $N$-vinylpyrrolidone) Copolymers with Double-Decker Silsesquioxane in the Main Chains: Synthesis, Glass Transition, and Self-Assembly Behavior. J. Polym. Sci. Part A: Polym. Chem. 2016, 54, 2949-2961; (f) Wang, L.; Zhang, C.; Zheng, S. Organic-Inorganic Poly(hydroxyether of bisphenol A) Copolymers with Double-Decker Silsesquioxane in the Main Chains. J. Mater. Chem., 2011, 21, 
19344- 19352; (g) Seino, M.; Hayakawa, T.; Ishida, Y.; Kakimoto, M.-A.; Watanabe, K.; Oikawa, H. Hydrosilylation Polymerization of Double-Decker-Shaped Silsesquioxance Having Hydrosilane with Diynes. Macromolecules 2006, 39, 3473-3475.

(15) (a) Żak, P.; Dudziec, B.; Dutkiewicz, M.; Ludwiczak, M.; Marciniec, B.; Nowicki, M. A New Class of Stereoregular Vinylene-Arylene Copolymers with Double-Decker Silsesquioxane in the Main Chain. J. Polym. Sci. Part A: Polym. Chem. 2016, 54, 1044-1055; (b) Żak, P.; Majchrzak, M.; Wilkowski, G.; Dudziec, B.; Dutkiewicz, M.; Marciniec, B. Synthesis and Characterization of Functionalized Molecular and Macromolecular Double-Decker Silsesquioxane Systems. RSC Adv. 2016, 6, 10054-10063; (c) Liu, N.; Wei, K.; Wang, L.; Zheng, S. OrganicInorganic Polyimides with Double Decker Silsesquioxane in the Main Chains. Polym. Chem. 2016, 7, 1158-1167; (d) Żak, P.; Dudziec, B.; Kubicki, M.; Mariniec, B. Silylative Coupling versus Metathesis-Efficient Methods for the Synthesis of Difunctionalized Double-Decker Silsesquioxane Derivatives. Chem. Eur. J. 2014, 20, 9387-9393; (e) Huang, J.; Wang, W.; Gu, J.; Li, W.; Zhang, Q.; Ding, Y.; Xi, K.; Zheng, Y.; Jia, X. New Bead Type and High Symmetrical Diallyl-POSS Based Emissive Conjugated Polyfluorene. Polymer 2014, 55, 6696-6707.

(16) (a) Schoen, B. W.; Lira, C. T.; Lee, A. Separation and Solubility of Cis and Trans Isomers in Nanostructured Double-Decker Silsesquioxanes. J. Chem. Eng. Data 2014, 59, 1483-1493; (b) Schoen, B. W.; Holmes, D.; Lee, A. Identification and Quantification of cis and trans Isomers in Aminophenyl Double-Decker Silsesquioxanes using ${ }^{1} \mathrm{H}_{-}^{29}$ Si gHMBC NMR. Magn. Reson. Chem. 2013, 51, 490-496; (c) Seurer, B.; Vij, V.; Haddad, T.; Mabry, J. M.; Lee, A. Thermal Transitions and Reaction Kinetics of Polyhedral Silsesquioxane containing Phenylethynylphthalimides. Macromolecules 2010, 43, 9337-9347.

(17) (a) Sodkhomkhum, R.; Ervithayasuporn, V. Synthesis of Poly(siloxane/Double-Decker Silsesquioxane) via Dehydrocarbonative Condensation Reaction and its Functionalization. Polymer 2016, 86, 113-119. (b) Ervithayasuporn, V.; Sodkhomkhum, R.; Teerawatananond, T.; Phurat, C.; Phinyocheep, P.; Somsook, E.; Osotchan, T. Unprecedented Formation of cis- and trans-Di[(3-chloropropyl)isopropoxysilyl]-Bridged DoubleDecker Octaphenylsilsesquioxanes. Eur. J. Inorg. Chem. 2013, 3292-3296.

(18) For $\mathrm{D}_{2} \mathrm{~T}_{8}$ DDSQ bearing two azido functions: (a) Ervithayasuporn, V.; Wang, X.; Kawakami, Y. Synthesis and Characterization of Highly Pure Azido-Functionalized Polyhedral Oligomeric Silsesquioxanes (POSS). Chem. Commun., 2009, 5130-5132; (b) Wei, K.; Wang, L.; Zheng, S. Organic-Inorganic Copolymers with Double-Decker Silsesquioxane in the Main Chains by Polymerization via Click Chemistry. J. Polym. Sci. A Polym. Chem. 2013, 51, 4221-4232.

(19) Liu, Y.; Takeda, N.; Ouali, A.; Unno, M. Synthesis, Characterization, and Functionalization of Tetrafunctional Double-Decker Siloxanes. Inorg. Chem. 2019, 58, 4093-4098.

(20) (a) Huisgen, R. Kinetics and reaction mechanisms: selected examples from the experience of forty years. Pure \& Appl. Chem., 1989, 61, 613-628; (b) Xi, W.; Scott, T. F.; Kloxin, C. J.; Bowman, C. N. Click Chemistry in Materials Science. Adv. Funct. Mater. 2014, 24, 2572-2590.

(21) (a) Ozdogan, R.; Daglar, O.; Durmaz, H.; Tasdelen, M. A. Aliphatic Polyester/polyhedral Oligomeric Silsesquioxanes Hybrid Networks via Copper-free 1,3-dipolar Cycloaddition Click Reaction. J. Polym. Sci. A Polym. Chem. 2019, 57, 2222-2227; (b) Chang, P.; Xu, S.; Zhao, B.; Zheng, S. A Design of Shape Memory Networks of Poly(E-caprolactone)s via POSS-POSS interactions. Polym. Adv. Technol. 2019, 30, 713-725; (c) Su, Z.; Hsu, C.H.; Gong, Z.; Feng, X.; Huang, J.; Zhang, R.; Wang, Y.; Mao, J.; Wesdemiotis, C.; Li, T.; Seifert, S.; Zhang, W.; Aida, T.; Huang, M.; Cheng, S. Z. D. Identification of a Frank-Kasper Z Phase from Shape Amphiphile SelfAssembly. Nature Chem. 2019, 11, 899-905; (d) Li, L.; Zhang, C.; Zheng, S. Synthesis of POSS-Terminated Polycyclooctadiene Telechelics via Ring-Opening Metathesis Polymerization. J. Polym. Sci. A Polym. Chem. 2017, 55, 223-233; (e) Ziarani, G. M.; Nahad, M. S.; Lashgari, N.; Badiei, A. Synthesis of a Nanostructured Composite: Oktakis(1-propyl-1H-1,2,3-triazole-4-yl(methyl-2-chlorobenzoate)octasilsesquioxane via Click reaction. Acta Chim. Slov. 2015, 62, 709-715; (f) Zheng, Y.; Wang, L.; Zheng, S. Synthesis and Characterization of Heptaphenyl Polyhedral Oligomeric Silsesquioxane-Capped Poly(N-isopropylacrylamide)s. Eur. Polym. J., 2012, 48, 945-955; (g) Wang, L.; Zheng, S. Surface Morphology and Dewettability of Self-Organized Thermosets Involving Epoxy and POSS-Capped Poly(ethylene oxide) Telechelics. Mater. Chem. Phys. 2012, 136, 744-754; (h) Jiang, Z.-Y.; Zhou, Y.; Huang, F.-R.; Du, L. Characterization of a Modified Silicon-Containing Arylacetylene Resin With POSS Functionality. Chin. J. Polym. Sci. 2011, 29, 726-731; (i) Binder, W. H.; Petraru, L.; Sachenshofer, R.; Zirbs, R. Synthesis of Surface-Modified Nanoparticles via Cycloaddition-Reactions. Monatshefte für Chemie 2006, 137, 835841.

(22) (a) Zhou, Y.; Yang, G.; Lu, C.; Nie, J.; Chen, Z.; Ren, J. POSS Supported C2-symmetric Bisprolinamide as a Recyclable Chiral Catalyst for Asymmetric Aldol reaction. Catal. Commun. 2016, 75, 23-27; (b) Zheng, W.; Lu, C.; Yang, G.; Chen, Z.; Nie, J. POSS Supported Diarylprolinol Silyl Ether as an Efficient and Recyclable Organocatalyst for Asymmetric Michael Addition Reactions. Catal. Commun. 2015, 62, 34-38; (c) Ervithayasuporn, V.; Kwanplod, 
K.; Boonmak, J.; Youngme, S.; Sangtrirutnugul, P. Homogeneous and Heterogeneous Catalysts of Organopalladium Functionalized-Polyhedral Oligomeric Silsesquioxanes for Suzuki-Miyaura Reaction. J. Catal. 2015, 332, 62-69.

(23) (a) Zhang, J.; Si, D.; Wang, S.; Liu, H.; Chen, X.; Zhou, H.; Yang, M.; Zhang, G. Novel Organic/Inorganic Hybrid Star Polymer Surface-Crosslinked with Polyhedral Oligomeric Silsesquioxane. Macromol. Res. 2019, DOI 10.1007/s13233-020-8021-4; (b) Doganci, M. D.; Aynali, F.; Doganci, E.; Ozkoc, G. Mechanical, Thermal and Morphological Properties of Poly(lactic acid) by Using Star-Shaped Poly(e-caprolactone) with POSS core. Eur. Polym. J. 2019, 121, 109316; (c) Uner, A.; Doganci, E.; Tasdelen, M. A. Non-Covalent Interactions of Pyrene EndLabeled Star Poly(E-caprolactone)s with Fullerene. J. Appl. Polym. Sci. 2018, 135, 46520; (d) Namvari, M.; Du, L.; Stadler, F. J. Graphene Oxide-Based Silsesquioxane-Crosslinked Networks - Synthesis and Rheological Behavior. RSC Adv., 2017, 7, 21531-21540; (e) Li, Y.; Wan, L.; Huang, F.; Du, L. Core-Shell Octa(azidopropyl)-POSS-PEO Micelle via "Click" Chemistry. J. Mol. Liq. 2014, 196, 238-243; (f) Yuan, W.; Liu, X.; Zou, H.; Li, J.; Yuan, H.; Ren, J. Synthesis, Self-Assembly, and Properties of Homoarm and Heteroarm Star-Shaped Inorganic-Organic Hybrid Polymers with a POSS Core. Macromol. Chem. Phys. 2013, 214, 1580-1589; (g) Yuan, W.; Liu, X.; Zou, H.; Ren, J. Environment-Induced Nanostructural Dynamical-Change Based On Supramolecular Self-Assembly of Cyclodextrin and Star-Shaped Poly(ethylene oxide) with Polyhedral Oligomeric Silsesquioxane Core. Polymer 2013, 54, 5374-5381; (h) Ge, Z.; Wang, D.; Zhou, Y.; Liu, H.; Liu, S. Synthesis of Organic/Inorganic Hybrid QuatrefoilShaped Star-Cyclic Polymer Containing a Polyhedral Oligomeric Silsesquioxane Core. Macromolecules 2009, 42, 2903-2910; (i) Ak, M.; Gacal, B.; Kiskan, B.; Yagci, Y.; Toppare, L. Enhancing Electrochromic Properties of Polypyrrole by Silsesquioxane Nanocages. Polymer 2008, 49, 2202-2210.

(24) (a) Rahimifard, M.; Ziarani, G. M.; Badiei, A.; Yazdian, F. Synthesis of Polyhedral Oligomeric Silsesquioxane (POSS) with Multifunctional Sulfonamide Groups Through Click Chemistry. J. Inorg. Organomet. Polym. 2017, 27, 1037-1044; (b) Trastoy, B.; Bonsor, D. A.; Pérez-Ojeda, M. E.; Jimeno, M. L.; Méndez-Ardoy, A.; Garcia Fernández, J. M.; Sundberg, E. J.; Chiara, J. L. Synthesis and Biophysical Study of Disassembling Nanohybrid Bioconjugates with a Cubic Octasilsesquioxane Core. Adv. Funct. Mater. 2012, 22, 3191-3201; (c) Fabritz, S.; Heyl, D.; Bagutski, V.; Empting, M.; Ribowski, E.; Frauendorf, H.; Balog, I.; Fessner, W.-D.; Schneider, J. J.; Avrutina, O.; Kolmar, H. Towards Click Bioconjugations on Cube-Octameric Silsesquioxane Scaffolds. Org. Biomol. Chem., 2010, 8, 2212-2218; (d) Heyl, D.; Robowski, E.; Hoffmann, R. C.; Schneider, J. J.; Fessner, W.-D. A "Clickable" Hybrid Nanocluster of Cubic Symmetry. Chem. Eur. J. 2010, 16, 5544-5548.

(25) For azido-decorated T10: (a) Liu, G.; Feng, X.; Lang, K.; Zhang, R.; Guo, D.; Yang, S.; Cheng, S. Z. D. Dynamics of Shape-Persistent Giant Molecules: Zimm-like Melt, Elastic Plateau, and Cooperative Glass-like. Macromolecules 2017, 50, 6637-6646; (b) Feng, X.; Zhu, S.; Yue, K.; Su, H.; Guo, K.; Wesdemiotis, C.; Zhang, W.-B.; Cheng, S. Z. D.; Li, Y. $\mathrm{T}_{10}$ Polyhedral Oligomeric Silsesquioxane-Based Shape Amphiphiles with Diverse Head Functionalities via "Click Chemistry". ACS Macro Lett. 2014, 3, 900-905.

(26) Liu, Y.; Onodera, K.; Takeda, N.; Ouali, A.; Unno, M. Synthesis and Characterization of Functionalizable Silsesquioxanes with Ladder-type Structures. Organometallics 2019, 38, 4373-4376.

(27) (a) Apfel, U.-P.; Troegel, D.; Halpin, Y.; Tschierlei, S.; Uhlemann, U.; Görls, H.; Schmitt, M.; Popp, J.; Dunne, P.; Venkatesan, M.; Coey, M.; Rudolph, M.; Vos, J. G.; Tacke, R.; Weigand, W. Models for the Active Site in [FeFe] Hydrogenase with Iron-Bound Ligands Derived from Bis-, Tris-, and Tetrakis(mercaptomethyl)silanes. Inorg. Chem. 2010, 49, 10117-10132; (b) Klapötke, T. M.; Krumm, B.; Nieder, A.; Richter, O.; Troegel, D.; Tacke, R. Silicon-Containing Explosives: Syntheses and Sensitivity Studies of (Azidomethyl)-, Bis(azidomethyl)-, and Tris(azidomethyl)silanes. Z. Anorg. Allg. Chem. 2012, 638, 1075-1079.

(28) (a) Thorwirth, R.; Stolle, A.; Ondruschka, B.; Wild, A.; Schubert, U. S. Fast, ligand- and solvent free coppercatalyzed click reactions in a ball mill. Chem. Commun., 2011, 47, 4370-4372; (b) Sun, N.; Yu, Z.; Yi, H.; Zhu, X.; Jin, L.; Hu, B.; Shen, Z.; Hu, X. Synthesis of a heterogeneous $\mathrm{Cu}(\mathrm{OAc})_{2}$-anchored SBA-15 catalyst and its application in the CuAAC reaction. New J. Chem., 2018, 42, 1612-1616.

(29) (a) Cucciolito, M. E.; D’Amora, A.; De Feo, G.; Ferraro, G.; Giorgio, A.; Petruk, G.; Monti, D. M.; Merlino, A.; Ruffo, F. Five-Coordinate Platinum(II) Compounds Containing Sugar Ligands: Synthesis, Characterization, Cytotoxic Activity, and Interaction with Biological Macromolecules. Inorg. Chem. 2018, 57, 3133-3143. (b) Leonidova, A.; Pierroz, V.; Adams, L. A.; Barlow, N.; Ferrari, S.; Graham, B.; Gasser, G. Enhanced Cytotoxicity through Conjugation of a "Clickable" Luminescent Re(I) Complex to a Cell-Penetrating Lipopeptide. ACS Med. Chem. Lett. 2014, 5, 809-814. 